\title{
4
}

\section{Participative Simulation Game as Facilitator of Organizational Development Process - Two case studies}

Forssén-Nyberg, M., Researcher, PhD.

Helsinki University of Technology/TUTA, P.O.Box 9555, FIN02015 HUT, Finland, +358-9-4513654, Minna.Forssen@ hut.fi Kutilainen, $P$., Researcher

HUT /TUTA, P.O.Box 9555, FIN-02015 HUT, Finland, +3589-4514761, Paivi.Kutilainen@ hut.fi

\begin{abstract}
The main use of simulation games is developing business processes i.e. analyzing and testing processes and training of employees. It can be used as a tool in different phases of the organizational change process; in analysis, planning, testing, and implementation phase. According to the research results the participative simulation game method has proven to be an effective facilitator of the organizational change process.

The paper in based on a descriptions of two case-studies. Firstly the aim of this presentation is to describe the participative development processes, where simulation games were used as facilitators in the analysis phase. Secondly the paper will discuss the role of the simulation game and the other factors in terms of success of the implementation phase.
\end{abstract}

\section{Keywords}

Simulation game method, case study, food industry, printing house. 


\section{INTRODUCTION}

A simulation game is an interactive and participative development method which can be used in various phases of the development process (Haho \& Smeds 1997, Hakamäki \& Forssén-Nyberg 1996). It helps companies identify technical and non-technical problems within the organization and current business processes. It can be used to simulate information and material flows within the processes as well as aspects of internal and external communication. The simulation game can be used to create the ideal process and test and evaluate needed changes in the business processes before implementation. It is a good training method as well. The simulation game must always be tailored to the process and environment where it will be used as a development method.

According to the research results the participative simulation game method has proven to be an effective facilitator of the organizational change process (Haho \& Smeds 1996, Forssén-Nyberg \& Hakamäki 1997, Ruohomäki 1994). For instance a common understanding of the process increases employee motivation and commitment to changes.

\section{THE FOOD INDUSTRY CASE}

The case study concerned a food industry company and concentrated on development of the R\&D process by using a simulation game.

The R\&D process goes through several business functions: from marketing to the R\&D department forward to production and finally to delivery. Projects are carried out in two semi-annual cycles: the first launch is in spring, the second in autumn. Normally R\&D projects take half a year, though some may take longer. Several R\&D projects are active simultaneously.

The R\&D process can be simplified as follows: The product manager from a marketing department, who works as an $R \& D$ project manager, is responsible for project planning, advertising planning and packing material designing. She/he manages the whole project and makes decisions about the final product. Meanwhile the R\&D department is testing and choosing raw materials. R\&D assistants repair different kinds of samples according to the instructions received from a product manager. This testing phase of the process is called piloting.

Production tests follow piloting. Production can be divided into two phases: a trial trip and production. The aim of the trial trip is to find the right raw material combination and production run parameters. Production starts running when everything is tested and fixed. 


\subsection{Objectives}

The development project started in autumn 1996. The aim of the project was to model the R\&D process and to develop tools or methods for project management (e.g. scheduling). Simulation games were used in both phases: primarily to analyze the present state "as is" and to develop the ideal process as well.

More detailed goals were set for both simulation games. The objectives of the first were:

- to point out the problems and development needs of the present R\&D-process

- to increase the understanding and knowledge of personnel about the whole process

- to increase cooperation between employees

The objectives of the second simulation game were:

- to clarify the material and information flows in the process

- to model the "ideal" R\&D-process

- to derive concrete improvement ideas for the development work

\subsection{Simulation game project}

The simulation games were planned by the planning team. The planning team consisted of a production manager, product manager, $R \& D$ researcher, administrative manager (project manager) and two external facilitators (two researchers). Even though the researchers were principally responsible for the project, the company named one person, the project manager, to take responsibility for their side. (Figure 1)

Altogether the planning team had meetings twice before the first game and four times before the second. The aim of the planning team was to design the form of the games, to describe the work process, prepare and design all visual material, send invitations and prepare the game site. The researchers also collected data and information about the process by interviewing employees.

There were about 40 people participating in each simulation game. In addition there ware researchers acting as leader and the secretary. Representatives of material suppliers and advertising offices as well as customer and consumer delegates were also invited. 
The reseachers were involved 6 months

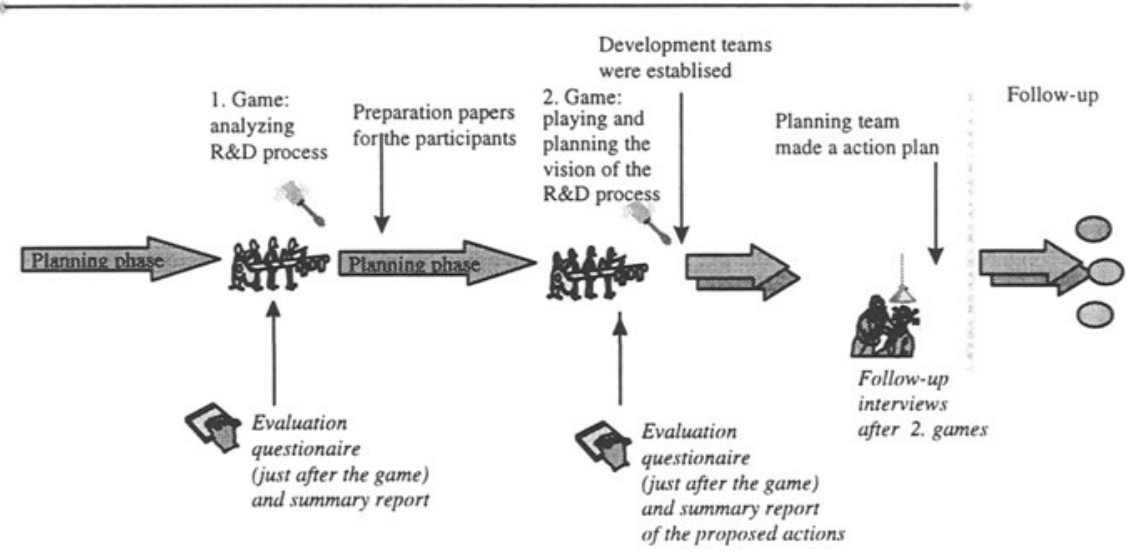

Figure 1. The development project of $R \& D$ process.

The first game

The first game round was used for analyzing the present state of the R\&D process. The process was visualized by a large process flowchart, which was placed on the wall. The day was divided into two parts: two game tours and one group task. Each player explained to the others his/her tasks in the process by answering the following questions:

- what he/she is doing

- what is produced and for whom

- what tools, material and information are needed and how to acquire them

- what problems exist with the present way of working

The players also showed their work area in the flowchart.

The second game round tour was based on analyzing the present situation through an example project selected from the recent past. The purpose was to simulate a real project and the typical problems that occurred. Before the game, all documentation related to the case example was collected.

A group work session was held after game. The objective of group work was to point out the five largest problems in the process and if possible, provide some improvement ideas.

The main development targets according to the results of the simulation games were: the beginning of the project (such as the content of the project plan, or who should be involved in the first project meeting), the planning of investments, the project management and the evaluation of projects. 
Altogether 38 employees filled out the evaluation questionnaire. According to the questionnaire, participants were satisfied with the days (Table 1): the average of the grade for all answers was 4.0 (on a scale of $1-5$, where $1=$ very much disagree and $5=$ very much agree). The most indispensable outcome according to the written answers was that the game increased the common understanding and knowledge of the process in general.

Table 1. The quantitative answers of the evaluation questionnaire (on a scale of 15 , where $1=$ very much disagree and $5=$ very much agree).

\begin{tabular}{|c|c|}
\hline Evaluated statements on the simulation games $(n=38)$ & Grades \\
\hline The game would also be useful for other employees in the company & 4.4 \\
\hline Participants have much opportunity to comment & 4.2 \\
\hline The game pointed out well the development needs in work processes & 4.1 \\
\hline The game increased knowledge about work processes & 4.1 \\
\hline It was useful for employees to participate & 4.4 \\
\hline The game bring up ideas of action plans & 3.4 \\
\hline
\end{tabular}

The second game

The second game was used as a tool for participative process redesign such as creating a mutual vision of the ideal process. The focus was on information and material flows. A preparation paper was sent to all participants. There were questions about "as is" information and material flows as well as the need to change the current situation.

A large project schedule was placed on the wall. An ideal project schedule was drawn up based on the process model.

The players represented different phases of the R\&D process. Each player explained the material and information needs from their point of view. Information or material needs were illustrated with a piece of paper attached to the corresponding place on the project schedule. If there was some kind of problem in information or material flows, it was marked with a red piece of paper. After every phase there was discussion about the problems, which the observers also took in.

The key finding was that it was impossible to build an ideal project model under current circumstances. To improve scheduling considerably would necessitate major changes in the operating model. Currently many scheduling objectives are contradictory, all necessary information is not available when needed and there is not enough time to take preparatory steps and actions for a new project. 
At the end of the day, every participant filled out an evaluation questionnaire. Results were summarized and reported back to the participants by the researchers. Altogether 31 employees filled out the evaluation questionnaire. According to the questionnaire, participants were satisfied with the days (Table 2): the average of the grade for all answers was 4.1 (on a scale of 1-5, where 1=very much disagree and $5=$ very much agree).

Table 2. The quantitative answers of the evaluation questionnaire (on a scale of 15 , where $1=$ very much disagree and $5=$ very much agree).

\begin{tabular}{|c|c|}
\hline Evaluated statements on the simulation games $(n=31)$ & Grades \\
\hline The game would also be useful for other employees in the company & 4.3 \\
\hline Participants have much opportunity to comment & 4.3 \\
\hline The game bring up ideas about action plans & 3.9 \\
\hline The game illustrated the ideal project & 3.8 \\
\hline It was useful for employees to participate & 4.5 \\
\hline The game illustrated material and information flows & 4.1 \\
\hline
\end{tabular}

The development teams were established after the games. The objective was to design an ideal process model based on the work carried out in the second phase and propose how to solve the problems marked with a red paper on the process schedule.

After the development teams finished their tasks, the planning group of the project made an action plan for the near future. The plan was presented to the development manager, the owner of the $R \& D$ process.

The researcher evaluated the development project by interviewing some of the participants one month after the second game. According to the interviews there were a lot of expectations about development action. Some people (workers, foremen) were a little disappointed not much has happened from their point of view. People expected more information on plans and decisions. On the other hand, managers told that some big changes in project management had appeared.

Nevertheless, some improvements were implemented immediately following the simulations games. The information flow between the piloting phase and production was improved. Many people said that it was much easier to communicate and give information to others after the games. More people were invited to project meetings to ensure communication on project status as well. The discussion on future projects began also much earlier than before. The quality 
system was improved. The new project schedule was used even though it was not suited to every project because of different project types.

All the people interviewed thought that the simulation game as a development method was a very good and interesting way to go through work processes and bring up related issues.

\section{THE PRINTING HOUSE CASE}

The case study was done in one part of a large printing house. This part was specialized in serving customers who needed leaflets, business cards or transparencies printed quickly. Around 25 were employed at this "express" press in 1995.

\subsection{Objectives}

The first aim of the project was to train employees to understand the whole orderdelivery process. The second was to improve customer service and "people" skills with the customers. The idea for this project originated with the training manager of the company.

\subsection{Simulation game project}

The planning team was established at the beginning of the project. The team included representatives from every work phase of the "express" press (workers and managers), as well as a researcher as a facilitator, totaling eight people. The planning team chose three products for which the order-delivery processes were simulated and drew up the first version of the process flow charts.

The game was designed in a participative way (see: Forssén-Nyberg \& Hakamäki 1997). The process flowcharts were drawn in more detail and the typical problems of the work process were defined together with employees. In addition to collecting data with the employees the researcher met customers of the three products. The preparation carried out in Spring 1995 was conducted by a researcher. (Figure 2) 

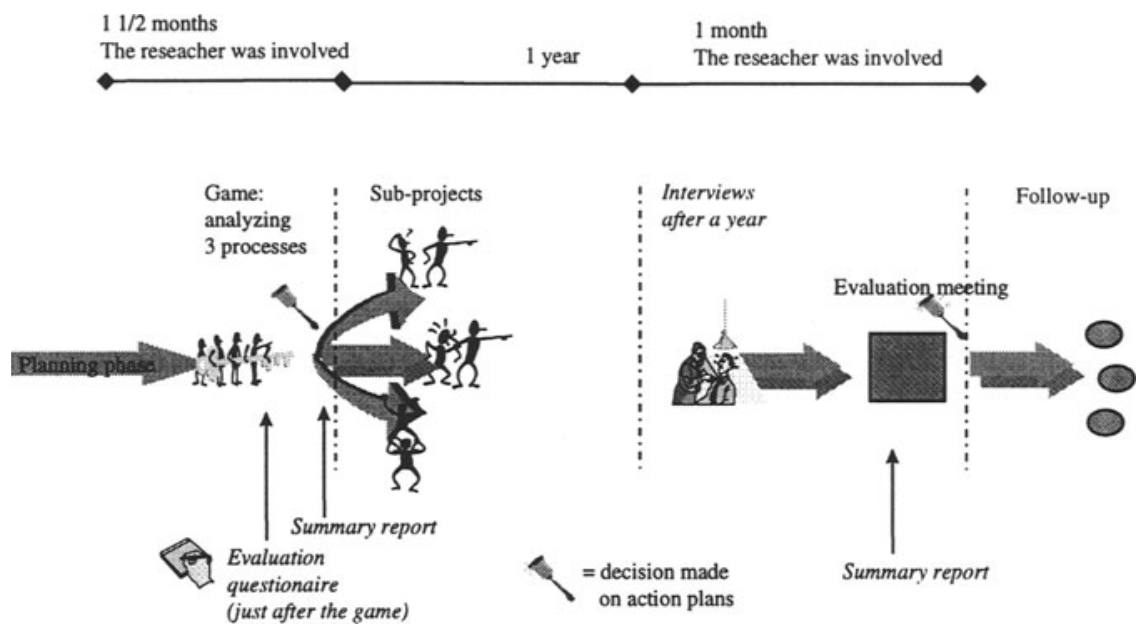

Figure 2 . The process of the printing house case

The game itself took one day (eight hours). It included three separate simulation games and a summary discussion. Thirty-two employees of the company participated in the simulation game as well as two researchers, the facilitator of the game and the secretary. The customers of the three products were also invited to the simulation game to each play the role of customer.

Table 3. Example action plans.

Action
Customer training
Send renewed mailing list to press
where the mailing process could
be made easier

Test and choose new raw

The customer and the

Dead-line

Responsibility

End of summer

manager of the press

materials (paper) to achieve a

press

better printing result

Customer Right away


The secretary collected the development needs suggested by players or observers during the simulation games. After the games we discussed the development needs and how to proceed with them. From the summary discussion we were able to outline an action plan (what will be done, by whom, and when ) (Table 3).

At the end of the game, every participant filled in the evaluation questionnaire. The researcher took the minutes of the simulation game day, mailed to all participants after the game.

Both quantitative and qualitative methods were used to collect data on participants experiences. Altogether 28 employees filled in the evaluation on a simulation game, which included 15 questions. According to the questionnaire, participants were content for the day (average grade of all answers was 4.2 on a scale of 1-5, where $1=$ very much disagree and $5=$ very much agree). The game increased the comprehension and knowledge of personnel about three work processes from start to finish (grade 4.4) (Table 4), which the written statements support. They felt that it was useful for them (4.4) and would be useful for others (4.5) as well. According to the responses the most telling outcome was the opportunity to get to know and talk to people from other departments. The lowest scores were given to information about production costs (3.8)

Table 4. The quantitative answers of the evaluation questionnaire (on a scale of 15 , where $1=$ very much disagree and $5=$ very much agree).

Statements evaluated for the simulation games $(n=28)$ Grade

The game would be useful for other employees of the company 4.5

Participants have good opportunity to comment 4.1

The game pointed out well the cause-effect relationships in work 4.3

processes

The game increased knowledge of three work processes 4.4

It was useful for employees to participate 4.4

The game provided information about production costs 3.8

The following spring (May-June 1996) the researcher conducted follow-up interviews. The aim of the interview was to evaluate the results of the simulation game project and the impetus for this follow-up came from the researcher. She interviewed two customers and 15 employees who participated in the game the previous year. The interview included questions about action plans, whether those actions had taken place and if not, what were the reasons. 
Many interviewees indicated that it is essential to write down the action plans right after the game and then do a follow-up, otherwise things do not happen: the follow-up is imperative in terms of achieving results. The follow-up should thus be a continuous process such as twice a year and not just once was this case. Employees of the press as well as customers said that working together became easier after the game.

The researcher presented a summary of the interviews at the evaluation meeting to which all participants of the simulation game were invited. According to the follow-up interview nine out of thirteen actions were completed. As a result of the evaluation meeting some new action plans were drawn up; one customer representative, for instance would visit the printing house to see the process, test and change printing inks for one product to make production more runnable and decrease the passing through time. The follow-up of these actions is responsibility of the press as the researcher was no longer involved.

\section{CONCLUSIONS}

The results from these case studies support the results of earlier studies: the simulation game is an effective participative method of learning for example increasing common understanding of the work process. The simulation game is a very good tool for training people to see both their role in the work process and the process as a whole, to collect vital information from employees about problems and development needs and to commit people into the change. Still, it is just one tool and the real development work, "hard work" starts after the game as was seen in both cases.

Secondly, the follow-up is very important for the success of the project. Decisions are made easily at meetings, but too often implementation fails. A systematic follow-up is a driving force of implementation.

Thirdly the facilitator of the project can either be an outsider or a organization's internal change agent. According to the interviewees of the press, little would have happened without a facilitator from outside, especially as it was the first time simulation games were used in the company. The role of the outsider was essential in the simulation game, where she was a facilitator, as well as in the follow-up phase.

Fourthly the work of the planning team was very successful. The roles on the team were clear: company representatives offered their knowledge of the substance and the researchers their knowledge of the development method. With researchers and representatives of company planning the game together, these two areas of knowledge were integrated efficiently.

Finally, according to the results of the food industry case it would be possible to use a simulation game method in different phases of a development process and for different purposes. Using the simulation game several times encourages people to 
participate in development during the whole project. After the first game the method becomes familiar, so it is much easier to participate in subsequent games.

\section{REFERENCES}

Forssén-Nyberg, M. \& Hakamäki, J. (1997) Development of the production using participative simulation games: two case studies. Forthcoming in: International Journal of Production Economics.

Haho, P. \& Smeds, R. (1997). The Softmatch-method: Enterprise Transformation through Simulation Games. Danny Saunders (eds.): The Simulation and Gaming Yearbook Volume 5. Kogan Page, London. (in print)

Haho, P. \& Smeds, R. (1996) Benefits from Using Simulation Games in Business Process Development. Experiences from a Finnish Manufacturing Company. In: Okino, N., Tamura, H. \& Fujii S. (eds.) Advances in Production Management Systems. 267-282.

Hakamäki, J. \& Forssén-Nyberg, M. (1996) Simulation game - a participative method for development. In: Koubek \& Karwowski (eds.): Manufacturing Agility and Hybrid Automation. Fifth International Conference on Human Aspects of Advanced manufacturing: Agility \& Hybrid Automation. August 7.-10. 1996, Maui, USA. IEA-press, USA. 575-579.

Ruohomäki, V. (1994) Simulation Games and their Effects - the Work Flow Game for the Development of Administrative Work. Licentiate thesis, Helsinki University of Technology, Industrial Management and Industrial Psychology, Report 156, Otaniemi. (in Finnish)

\section{BIOGRAPHY}

The authors work as a researchers in the Department of Industrial Management at Helsinki University of Technology. Their special fields are business process development, social simulation game method and participative organisation development.

Minna Forssén-Nyberg is a $\mathrm{PhD}$ and is preparing her doctoral dissertation about knowledge accumulation in organisations. 